\title{
O ATENDIMENTO AOS ALUNOS COM DEFICIÊNCIA NA ESCOLA MUNICIPAL CÍVICO MILITAR PROFESSOR VERÍSSIMO DE MELO (ECIM): O QUE DIZ A LEI E COMO DE FATO ACONTECE NO COTIDIANO DA ESCOLA
}

\author{
Afonso Ribeiro Damasceno Neto ${ }^{1}$ \\ Águida Dionízio Benevides de Paiva Figueira ${ }^{2}$ \\ Cristiano Araújo da Silva ${ }^{3}$ \\ Geilza de Lima Abdias da Silva ${ }^{4}$ \\ Jadna Tavares da Silveira ${ }^{5}$ \\ Josefa Poliana Clementino Ferreira ${ }^{6}$
}

RESUMO: Este artigo propõe-se a versar sobre os desafios enfrentados para a implantação da educação especial dentro da atual política de educação inclusiva, sobretudo no Brasil. Para tanto, apresentamos um breve histórico das diversas etapas e movimentos a respeito das diretrizes educacionais baseadas na segregação dos alunos com deficiência, que sustentaram a educação especial desde sua implantação até a adoção de uma política de matrículas na rede regular de ensino, dessa forma propõe a junção das crianças com ou sem deficiências em salas de aulas comuns das escolas públicas. Discutimos as condições de implantação da

\footnotetext{
${ }^{1}$ Graduado em Física licenciatura pela UFRN 2002/2005 Professor efetivo do estado RN e Município Parnamirim Mestrando em educação Assessoria e Consultoria Educacional (ESL) E-mail: afonsoribeiro2oo6@gmail.com. ${ }^{2}$ Graduada em Pedagogia Unifacex. 2005.I até 2009.I Pós-graduada em Psicopedagogia clínica e institucional Universidade Potiguar - UNP Conclusão em 2016 Mestranda em educação Assessoria e Consultoria Educacional (ESL) E-mail: aguida_dionizio@hotmail.com.

${ }^{3}$ Graduado em pedagogia - UVA (Universidade Estadual Vale do Acaraú) conclusão ano 2or8; Bacharel em Direito Universidade Potiguar (UNP), Conclusão 2020, Pós-Graduação: Docência na Educação Infantil e Anos Iniciais Universidade Cândido Mendes (UCAM), Conclusão 2020. Mestrando em educação Assessoria e Consultoria Educacional (ESL) E-mail: cristiano29_araujo@hotmail.com.

${ }^{4}$ Graduada em pedagogia -UVA (Universidade Estadual Vale do Acaraú) - conclusão ano 2009 Especialista em Educação Especial e Inclusiva - Faísa (Faculdade Santo Augusto) conclusão 2015, Especialista em Educação de Jovens e Adultos no contexto da Diversidade- IFRN Campus Canguaretama/RN) Instituto Federal de Educação, Ciência e Tecnologia do Rio Grande do Norte, conclusão 2017,

Especialista em Psicopedagogia Clínica e Institucional - FACEN (Faculdade de Ciências Educacionais e Empresariais de Natal) - conclusão 2020. Mestranda em educação Assessoria e Consultoria Educacional (ESL)

E-mail: geilzazo_lima@hotmail.com.

5 Graduada em bacharelado em Estatística - Universidade Federal do Rio Grande do Norte (UFRN) - 19972001

Graduação em licenciatura plena Matemática - Universidade Federal do Rio Grande do Norte (UFRN) - 2006/2010, Especialização em Ensino da Matemática: pela Universidade Vale do Acara (UVA) -2010/20II Especialização em português e Matemática uma proposta transdisciplinar - Instituto Federal do Rio Grande do Norte (IFRN) - 2013/2014. Mestranda em educação Assessoria e Consultoria Educacional (ESL)

Professora de Matemática efetiva e em exercício na sala de aula da rede municipal do Natal e de Lagoa de Pedras. Email: jad_silveira@hotmail.com.

${ }^{6}$ Graduada em Matemática Licenciatura Plena pela Universidade Federal do Rio Grande do Norte - UFRN (2005.2 Especialista em Práticas Educativas no Ensino Médio - Matemática pela Faculdade de Natal - FAL (2008.2)

Especialista em Educação Matemática: Teoria e Prática no Ensino Fundamental pelo Instituto de Educação Superior Presidente Kennedy (2009.2) Mestranda em educação Assessoria e Consultoria Educacional (ESL)

Professora Efetiva da rede Estadual do Rio Grande do Norte e da rede municipal do Natal/RN. E-mail: poliana.ferreira.mat@gmail.com
} 
proposta do Governo Federal de um "sistema educacional inclusivo", que conta com um suporte de atendimento educacional especializado para complementar e suplementar a educação escolar. Outro ponto importante desse artigo é a discussão sobre a adequação do projeto político pedagógico para tornar a escola um espaço para todos, possibilitando que os alunos construam o conhecimento segundo suas capacidades e se desenvolvam como cidadãos nas suas diferenças, esse processo passa pela reestruturação física e pedagógica da escola, a adequação do currículo que garanta que o aluno de fato se sinta acolhido e incluindo, isso precisa ir além de sua socialização. Por fim apresentamos como se deu a implantação da sala e recursos multifuncional conjuntamente com o ensino educacional especializado na escola Municipal Cívico Militar professor Veríssimo de Melo, localizada na zona oeste da cidade de Natal/RN, visando acolher os alunos com deficiência com mais eficácia. Concluímos confirmando a importância dessas politicas públicas para os alunos com deficiência, porém ressaltando que ainda temos um grande caminho a percorrer para que de fato elas se desenvolvam conforme os parecerem que a regem.

Palavras-chave: Educação Especial.Educação Inclusiva. Recursos Multifuncionais.

ABSTRACT: This article proposes to discuss the challenges faced for the implementation of special education within the current inclusive education policy, especially in Brazil. For this purpose, we present a brief history of the various stages and movements regarding educational guidelines based on the segregation of students with disabilities, which supported special education from its implementation to the adoption of an enrollment policy in the regular school system. the bringing together of children with or without disabilities in common classrooms in public schools. We discussed the conditions for implementing the Federal Government's proposal for an "inclusive educational system", which has specialized educational support to complement and supplement school education. Another important point of this article is the discussion on the adequacy of the pedagogical political project to make the school a space for everyone, enabling students to build knowledge according to their abilities and develop as citizens in their differences. This process goes through physical and pedagogical aspects of the school, the adequacy of the curriculum to ensure that the student actually feels welcomed and included, this needs to go beyond their socialization. Finally, we present how the multifunctional classroom and resources were implemented together with specialized educational teaching at the Municipal Civic Military School teacher Veríssimo de Melo, located in the west side of the city of $\mathrm{Natal} / \mathrm{RN}$, aiming to accommodate students with disabilities more effectively. We conclude by confirming the importance of these public policies for students with disabilities, but emphasizing that we still have a long way to go so that they actually develop as they appear to govern them.

Keywords: Special Education. Inclusive education. Multifunctional Features.

\section{Histórico do Surgimento da Educação Especial}

O modelo educacional destinado às pessoas com deficiência é algo que vem passando por um grande desenvolvimento ao longo das décadas. Mesmo assim, trata-se de um 
processo que evolui em passos lentos em termos práticos, apesar de estar em constante construção até hoje na busca de uma educação inclusiva.

É visível que a categoria da educação para pessoas com deficiência mudou bastante com o passar dos tempos em todo o mundo. Essas mudanças se iniciaram na Europa, por volta do fim do século XVIII, época na qual foram criados os primeiros institutos para cegos. Nesse período também surgiram os primeiros movimentos em prol do atendimento aos deficientes, que refletiram em inúmeras mudanças na atitude das pessoas, consolidando-se em medidas educacionais que percebiam os deficientes como cidadãos que deveriam ter seus direitos garantidos, tendo acesso a uma educação onde pudessem desenvolver suas potencialidades dentro de suas limitações.

Entendemos que nesse momento histórico pensar em inclusão ainda era um pouco utópico. Porém, a partir da disseminação dessas ideias, outros países iniciaram seus próprios movimentos que trouxeram um novo olhar para os deficientes, dando início ao processo de inclusão.

Vamos enfatizar os movimentos que impulsionaram as mudanças no Brasil, onde na verdade tínhamos até então um cenário de abandono e exclusão. Somente no século XIX, surgiram os primeiros institutos para pessoas com deficiência. No ano de 1854 , o instituto para meninos cegos, atual Instituto Benjamim Constant e, no ano de 1857 o instituto para surdos mudos, chamado de Instituto Nacional de Educação de Surdos, ambos no Rio de Janeiro. Porém, as limitações físicas e intelectuais ainda eram excluídas dessas discussões. Somente em meados do século XX se começou a pensar em Políticas de Educação Especial para atender essa parcela de pessoas com as deficiências que ainda não eram assistidas. Com isso vieram algumas mudanças, tais como: o surgimento de instituições como a sociedade Pestalozzi do Brasil e a APAE (Associação de Pais e Amigos dos Excepcionais). Todavia essas iniciativas ainda eram ínfimas ao se pensar em inclusão.

De fato, somente na década de 1980 a educação especial passou a ter um caráter de inclusão. O marco para isso foi a constituição de 1988, que em seu artigo 208, no capítulo III, garantiu $o$ atendimento educacional especializado as pessoas com deficiência preferencialmente na rede regular de ensino. Essa distinção foi consolidada em dezembro de 1996 com a publicação da Lei de Diretrizes e Bases da Educação Nacional, Lei 9.394/96. O texto deixava claro que a educação especial deveria ser oferecida preferencialmente na rede regular de ensino que disponibilizaria serviços de apoio especializados. A partir disto, a Educação Especial tomou outras orientações e, novos pensadores começaram a versar sobre o tema, desencadeando assim, o surgimento de novas metodologias de ensino e tecnologias inovadoras buscando uma educação mais inclusiva e significativa.

No Brasil, a educação de pessoas com deficiência de modo geral só passou a ser discutida com mais intensidade após a Declaração de Salamanca. Esse documento foi elaborado na Conferência Mundial sobre Educação Especial, na cidade de Salamanca, na Espanha, em 1994, com o objetivo de embasar diretrizes básicas para a formulação e reforma de políticas e sistemas educacionais de acordo com o movimento de inclusão social. A Declaração de Salamanca tem em sua base a seguinte ideia:

O princípio fundamental das escolas inclusivas consiste em todos os alunos aprenderem juntos, sempre que possível, independentemente das dificuldades e das diferenças que apresentem. Estas escolas devem reconhecer e satisfazer as necessidades diversas dos seus alunos, adaptando-se aos vários estilos e ritmos de aprendizagem, de modo a garantir um bom nível de educação para todos, através 
de currículos adequados, de uma boa organização escolar, de estratégias pedagógicas, de utilização de recursos e de uma cooperação com as respectivas comunidades. É preciso, portanto, um conjunto de apoios e de serviços para satisfazer o conjunto de necessidades especiais dentro da escola. (DECLARAÇÃO DE SALAMANCA, I994, p. II -I2).

Essa declaração foi de extrema importância para o processo de inclusão dos alunos com deficiência nas escolas ditas para normais e foi através dela que eles passaram a ter direito garantido a frequentar esses ambientes educacionais. Não podemos esquecer que essa declaração também enfatiza a importância de as escolas estarem preparadas para atender a esse público no que diz respeito a espaços físicos, pessoal especializado e currículo adaptado. Enfatizando a importância do apoio de toda a comunidade escolar nesse contexto.

A autora adiante acredita que a proposta trazida pela declaração de Salamanca está muito longe de ser atendida mesmo depois de anos de sua publicação. Na concepção de Mantoan (2006), esses direcionamentos ainda estão distantes de serem alcançados, pois a maioria das escolas simplesmente não estão adequadas estruturalmente, pedagogicamente e, principalmente, em termos de percepção de uma estruturação na forma de ensinar e avaliar. Por isso, é de extrema importância exigir que seja cumprido o que manda a lei, para que essas conquistas não se percam nessa falsa visão de inclusão. A autora supracitada enfatiza que:

\footnotetext{
A igualdade abstrata não propiciou a garantia de relações juntas nas escolas. A igualdade de oportunidades, que tem sido a marca das políticas igualitárias e democráticas no âmbito educacional, também não consegue resolver o problema das diferenças nas escolas, pois elas escapam ao que essa proposta sugere, diante das desigualdades naturais e sociais. (MANTOAN, 2006, p. 19)
}

Em nosso entendimento é notório que a Educação Inclusiva não foi implantada seguindo os pressupostos ditados na declaração de Salamanca sendo observado que se desenvolveu muito mais pelos caminhos citados por Mantoan (2006). Dessa forma, a Educação Inclusiva foi desenvolvida na perspectiva de que o aluno com deficiência tinha capacidade de aprender de acordo com sua disposição e competência, de construir o conhecimento de acordo com o currículo padrão da escola na qual estava matriculado, e que, ele se adaptava e avançava ou simplesmente ficaria retido. Ou seja, nessa perspectiva o currículo escolar e corpo docente em nada tinham que mudar, era o estudante que deveria se adequar aos moldes já existentes. Dessa maneira, a escola continuava sendo excludente pois não oportunizava aos alunos com deficiência a equidade referente ao desenvolvimento de suas potencialidades e habilidades na aquisição do saber.

A nosso ver a proposta de inclusão presente no documento citado é bem mais abrangente colocando que, na verdade, o que deveria ser levado em consideração era as limitações e peculiaridades que cada estudante tem dentro de sua deficiência. Desse modo, além do acesso à escola comum, seria necessário um acompanhamento especializado de acordo com a sua necessidade apresentada e uma assistência educacional particularizada. Isso vai muito além de apenas serem inseridos em ambientes de sala de aula comum.

Pensar em educação inclusiva não é somente socializar o aluno. Precisa-se pensar em uma reestruturação física e pedagógica, bem como modificações curriculares para que o ensino-aprendizagem faça sentido e abra espaço para a participação de todos os estudantes, 
além de estar conectado com a realidade. Os alunos com deficiência quando chegam a escola são de certa forma vistos como especiais. Todavia, ao final do ano letivo, é exigido que tenham adquirido um certo percentual de conceitos e habilidades referentes ao ano de escolaridade cursado para que possam ser promovidos. Esse fato faz a educação inclusiva perder sua essência tornando-se um ensino tradicional no qual a escola transmiti conteúdos que constam em um currículo obsoleto e, esses conteúdos precisam ser apreendidos por todos os estudantes igualmente sem distinção, o que torna discrepante essa situação mesmo para os alunos que não tem deficiência. Diante desses fatos percebe-se que a escola não está conseguindo cumprir seu papel social no âmbito da inclusão.

Todos esses pressupostos colocam e garantem um lugar para a Educação Especial como modalidade de ensino de grande importância e indispensável para a inclusão dos alunos com deficiência nas escolas comuns, sendo que não a substitui como escolarização devendo caminhar de forma integrada, dando suporte para que os estudantes matriculados em salas regulares se sintam mais integrados. A educação especial visa dar subsídios para que esses alunos com deficiência tenham acesso ao ambiente e ao conhecimento escolar regular de forma mais significativa e adaptável, não servindo apenas de espaço de socialização para eles e possibilitando que o espaço da sala de aula comum seja um ambiente inclusivo e sem exceções. Nesse entendimento a educação especial irá subsidiar o ensino na sala regular possibilitando uma melhor adaptação e, consequentemente, um aprendizado mais significativo dentro das limitações de cada deficiência.

A Política da Educação Especial vem apontando para a necessidade de se discutir a prática de ensino sob um olhar da educação inclusiva para atender os alunos com especificidades educacionais especiais que são seu público alvo. Para isso conta com a parceria do serviço do Atendimento Educacional Especializado - AEE que geralmente ocorre na sala de recursos multifuncionais.

A discussão desse modelo de educação inclusiva no ambiente escolar rompe com o modelo de escola que tínhamos até então, segregadora, no qual existiam escolas para alunos ditos "normais" e "especiais". Essa separação deixa de existir e dá espaço a concepção de identidade e diferença.

Para embasar nossa fala trazemos a percepção de Mantoan e Prieto quando destacam a importância de valorizar as peculiaridades de cada ser, sem de fato compara-los.

Quando entendemos que não é a universalidade das espécies que define um sujeito, mas as suas peculiaridades, ligadas a sexo, etnia, origem, crenças, tratar as pessoas diferentemente pode enfatizar suas diferenças, assim como tratar igualmente os diferentes pode esconder as suas especificidades e excluí-los do mesmo modo; portanto, ser gente é correr o risco de ser diferente. MANTOAN E PRIETO ( 2006, p. 17)

As autoras deixam claro que a individualidade de cada pessoa precisa ser percebida, não rotulando ou tendo uma receita a seguir para tratar um grupo de pessoas que possam apresentar características semelhantes, e sim que, cada um precisa ser apreciado em sua heterogeneidade.

Dessa forma os rótulos perdem sua capacidade de determinar a identidade dos estudantes, que alguns educadores, talvez por desconhecerem acabavam por assim denomina-los. Isso deixa de existir diante dos princípios da educação inclusiva, pois identidade não é versada como natural, firme, eterna, terminada. No ponto de vista da inclusão escolar, as identidades são momentâneas, variáveis e, consequentemente, os alunos 
não podem ser registrados em grupos, categorias definidas erroneamente por professores e gestores.

\begin{abstract}
A diferença, para a educação inclusiva, é vista como decorrente da multiplicidade, e não da diversidade como é comumente anunciada. A educação inclusiva inquire a superficialidade das identidades normais e busca garantir o direito à diferença $\mathrm{e}$ não a diversidade, pois, o contrário seria confirmar, validar o idêntico. A diferença (vem) do múltiplo e não do diverso. Tal como ocorre na aritmética, o múltiplo é sempre um processo, uma operação, uma ação. A diversidade é estática, é um estado, é estéril. A multiplicidade é ativa, é fluxo, é produtiva. A multiplicidade é uma máquina de produzir diferenças - diferenças que são irredutíveis à identidade. A diversidade limita-se ao existente. A multiplicidade estende e multiplica, prolifera, dissemina. A diversidade é um dado - da natureza ou da cultura. A multiplicidade é um movimento. A diversidade reafirma o idêntico. A multiplicidade estimula a diferença que se recusa a se difundir com o idêntico. (SILVA, 2000, p. I00-Ior apud RAPOLI, 2010, p. 8)
\end{abstract}

De fato a escola deveria compreender a diversidade como uma forma que engloba coletividade de idênticos, constituídos pelos próprios alunos de acordo com suas aptidões, peculiaridades, características. Quando nos referimos à escola aberta à diversidade, legitimamos que queremos extinguir a ideia de agrupar os alunos por suas especificidades como era feito antes nas escolas ditas comuns e especiais e, proporcionarmos um espaço comum a todos onde o aluno é que busca seu grupo de convivência de acordo com as suas disposições.

Nas escolas inclusivas não há identificação de alunos normais e especiais, todos são iguais pelas suas diferenças e constroem o conhecimento de acordo com as suas capacidades. As práticas de ensino devem ser revistas para que não sirvam de exclusão e se adaptem aos propósitos de uma escola para todos.

O ambiente educacional das diferenças é uma escola com ponto de vista de educação inclusiva e sua instrução tem como tema indagar, debater e refazer rotinas e convenções que, até pouco tempo eram impostas aos educandos onde os que não se adaptaram eram excluídos e encaminhados a outros ambientes educacionais diferentemente do que é proposto pela escola das diferenças.

Quando a escola reconhece as diferenças dos alunos no desenvolvimento do processo educativo e procura a cooperação e engajamento no progresso de todos, ela se torna uma escola inclusiva. Esse procedimento não é fácil e nem tão pouco imediato, mas com interesse e participação de todos os envolvidos no processo educacional, revisando práticas pedagógicas e fazendo os devidos ajustes, é possível sim a escola comum tornar-se a escola das diferenças e não a escola dos diferentes.

Em Brasil (2017), temos o documento norteador da educação básica que é a Base Nacional Comum Curricular (BNCC). Nele, observamos o pressuposto de uma educação abrangente sem diferenciação entre os estudantes uma vez que, apresenta uma proposta de ensino essencial para todos com uma educação justa, democrática e inclusiva, com princípios de respeito, empatia e colaboração. No qual os conteúdos deixaram de ser o ponto mais importante e o foco principal da educação passa ser as pessoas, dessa forma, toda a escola precisa pensar em uma educação inclusiva.

O município de Natal ainda não disponibiliza em toda a sua rede de ensino de profissionais capacitados para atender os alunos com deficiência, apesar disso, as escolas não 
podem se recusar a matricular nenhum aluno com essa especificidade. Portanto, é de práxis, que os educandos com alguma necessidade educacional especial sejam encaminhados para as escolas polos da rede municipal de ensino que são contempladas com os atendimentos de AEE (atendimento educacional especializado), e com salas de recursos multifuncionais. Esses ambientes são compostos por materiais que facilitam o aprendizado dos estudantes com inúmeras deficiências, além de um profissional capacitado para o atendimento especializado. Os discentes frequentam a sala comum e, além disso, participam no contra turno, de atividade individualizada de acordo com a sua necessidade especificada no AEE, que ocorre na sala de recursos multifuncionais, que em sua maioria são atividades com materiais concretos e manipuláveis os quais facilitam a aprendizagem devido a sua ludicidade.

\section{O Projeto Político Pedagógico, liberdade e administração igualitária}

O Projeto Político Pedagógico (PPP) é a identidade da escola, seu principal documento. Sendo o norteador desse ambiente, o qual dará apoio a todas as mudanças e ajustes necessários para que esse se torne um espaço educacional inclusivo. O mesmo é elaborado com a participação e contribuição da comunidade escolar a qual tem como base as peculiaridades do ambiente em questão, ou seja, ele é feito e refeito pensando em todas as questões pertinentes a qualidade e desenvolvimento do ensino neste lugar educacional. Esse documento é construído pela comunidade escolar, alunos, pais, professores, funcionários e gestores sendo de suma importância para a condução da deliberação das demandas no ambiente escolar de acordo com suas ações planejadas.

Esse projeto, construído em coletividade na comunidade escolar, deve estar sempre em uso e prática, pois auxilia a tomada de decisões e dá suporte a escola para que esta tenha um bom funcionamento e rendimento acadêmico visto que, sua elaboração é baseada na realidade escolar. Ressaltando que o PPP é um documento vivo que poderá ser revisado e implementado sempre que haja necessidade, ou seja, ele nunca vai estar pronto e acabado, pois sempre irão surgir novas situações que deverão ser colocadas em pautas para se tornarem parte integrante desse documento.

A Lei de Diretrizes e Bases da Educação Nacional - Lei $\mathrm{N}^{\circ}$ 9.394/96, em seu artigo I2, discorre sobre a responsabilidade dos estabelecimentos de ensino elaborar e executar suas propostas pedagógicas. Nossa legislação educacional é bem explícita quanto a responsabilidade da escola no que diz respeito ao processo de construção e propósito do PPP.

\section{A função do AEE}

O Atendimento Educacional Especializado (AEE), foi instituído pela Política nacional de educação especial na perspectiva da educação inclusiva, em 2008. Essa foi e ainda é uma das grandes conquistas, sendo de fundamental importância para garantir uma educação para todos. A Política garante a matrícula das pessoas com deficiência na escola regular e estabelece diretrizes para a criação de políticas públicas e práticas pedagógicas voltadas à inclusão escolar. Além disso, reformula o papel da educação especial, que passa a integrar a proposta pedagógica da escola por meio do AEE. Esse atendimento funciona como um recurso de essencial importância para a Inclusão Escolar de pessoas com deficiência. São muitas as possibilidades de abordagem para a estruturação do AEE e, geralmente, cada escola 
desenvolve uma proposta de trabalho diferente, haja vista que cada escola recebe alunos com diferentes deficiências, precisando esses atendimentos serem direcionados e específicos.

O foco desse suporte é identificar, elaborar e organizar diversos recursos pedagógicos e de acessibilidade de forma que na eliminação das barreiras para a participação integral dos estudantes com as especificidades de suas deficiências, de forma que alcancem autonomia e independência na escola além dos seus muros. E para que isso aconteça precisa existir um trabalho cooperativo de toda a escola, principalmente, entre o professor da sala regular e o responsável pelo o AEE. O planejamento entre esses profissionais precisa ser compartilhado, caso contrário ele perde seu sentido e deixa de cumprir sua função.

\section{Colaboração entre os discentes da sala de AEE e os discentes da sala comum}

$\mathrm{Na}$ educação inclusiva é garantido por lei que todos têm direito ao mesmo currículo e ao mesmo conjunto de saberes. Sendo de responsabilidade do docente da sala de aula comum planejar e, quando possível, adequar para todos os estudantes com ou sem deficiência. Mas essa tarefa pode - e deve - ser compartilhada com o docente da sala de recursos visto que, quando esses docentes ativamente participam propondo atividades condizentes com as vivências e habilidades dos alunos com deficiência, tornam o trabalho de ambos mais significativos e eficazes para o aprendizado e desenvolvimento dos alunos. Com essa interação é criada a oportunidade de ser trabalhada atividades considerando os interesses e as necessidades de cada aluno com deficiência, identificando possíveis barreiras à aprendizagem desses estudantes e apontando estratégias para que eles tenham as mesmas possibilidades que toda a turma. Isso sim garante não só a igualdade de oportunidades, mas também a equidade.

\section{Implantação e funcionamento dos Materiais da sala de recursos multifuncionais (SRM)}

Esses recursos visam integrar cada vez mais a educação especial às escolas regulares, pois são uma forma de possibilitar e facilitar o acesso do aluno com deficiência. Isso é consolidado através de Política públicas, em destaque aqui a Política da Educação Especial, que vem apontando para a necessidade de se discutir a prática de ensino sob um olhar da educação inclusiva para atender os estudantes com especificidades educacionais especiais, que são seu público alvo dentro das escolas regulares. Para isso, é necessário a implantação nas escolas regulares do serviço do Atendimento Educacional Especializado (AEE), em forma de parceria, que geralmente ocorre na sala de recursos multifuncionais (SRM). Essas salas fazem parte de um programa do Ministério da Educação do Brasil que fornece alguns equipamentos de informática, mobiliários, materiais didáticos e pedagógicos que são organizados nesses espaços no interior da escola comum das redes de ensino para ofertar AEE.

Este ambiente deve apresentar condições de acessibilidade, se caracterizando pela presença de profissionais qualificados para abordar os recursos específicos para a oferta do apoio pedagógico ao estudante público-alvo da educação especial. Tendo como pressuposto preparar o estudante para desenvolver habilidades e utilizar instrumentos de apoio que facilitem o aprendizado do mesmo nas aulas regulares. 


\begin{abstract}
A organização de salas de recursos multifuncionais se constitui como espaço de promoção da acessibilidade curricular aos alunos das classes comuns do ensino regular, onde se realizem atividades da parte diversificadas, como o uso e ensino de códigos, linguagens, tecnologias e outros complementares à escolarização, visando eliminar barreiras pedagógicas, físicas e de comunicação nas escolas. (DUTRA; GRIBOSKI, 2006, p.19).
\end{abstract}

A implantação desse modelo de educação inclusiva no ambiente escolar rompe com o modelo de escola que tínhamos até então que mais excluía do que incluía de fato, pois as escolas selecionavam e separavam os alunos ditos "normais" dos "especiais". Essa seleção deixa de existir e abre espaço para nov as concepções e espaços iclusivos. Esses espaços dentro das escolas possibilitam ao aluno com deficiência ter acesso ao ensino regular bem como ser acompanhado em suas especificidades.

Dessa forma, vemos as salas de SRM na qual acontecem os AEE, como um ambiente de acolhimento desses alunos no qual o ensino acontece de uma maneira mais eficaz, haja vista que ele dispõe de materiais e pessoal especializado. Todavia, para uma escola implantar esta sala é preciso seguir alguns critérios, cabendo aos gestores dos sistemas de ensino definir se a escola se enquadra nos requisitos dos documentos oficiais que as regulamentam. Que são os seguintes, de acordo com Brasil (2010, p. Io):

- A secretaria de educação a qual se vincula a escola deve ter elaborado o Plano de Ações Articuladas - PAR, registrando as demandas do sistema de ensino com base no diagnóstico da realidade educacional;

- A escola indicada deve ser da rede pública de ensino regular, conforme registro no Censo Escolar MEC/INEP (escola comum);

- A escola de ensino regular deve ter matrícula de aluno(s) público alvo da educação especial em classe comum, registrado(s) no Censo Escolar/INEP, para a implantação da sala Tipo I

- A escola de ensino regular deve ter matrícula de aluno(s) cego(s) em classe comum, registrado(s) no Censo Escolar/INEP, para a implantação da sala de Tipo II;

- A escola deve ter disponibilidade de espaço físico para o funcionamento da sala e professor para atuação no AEE.

As escolas, seguindo esses critérios, são indicadas pela secretaria Municipal de Educação, a qual se responsabiliza por fazer cumprir todas as normas exigidas para a implantação constantes em Brasil (2010, p. Io).

- Adesão e cadastro do gestor do Município (Prefeito), Estado ou Distrito Federal (Secretário de Educação);

- Indicação das escolas conforme os critérios do Programa;

- Confirmação de espaço físico para a sala;

- Confirmação de professor para atuar no AEE;

Em continuidade aos passos supracitados, em especial depois da confirmação da indicação da escola e da disponibilidade do espaço físico para a implantação da sala de AEE pelo Programa, as secretarias de educação devem fazer o seguinte (BRASIL, 20I0, p. II):

- Informar às escolas sobre sua indicação;

- Monitorar a entrega e instalação dos recursos nas escolas;

- Orientar quanto à institucionalização da oferta do AEE no PPP; 
- Acompanhar o funcionamento da sala conforme os objetivos;

- Validar as informações de matrícula no Censo Escolar INEP/MEC;

- Promover a assistência técnica, a manutenção e a segurança dos recursos;

- Apoiar a participação dos professores nos cursos de formação para o AEE;

- Assinar e retornar ao MEC/SEESP o Contrato de Doação dos recursos.

A sala de SRM na Escola Municipal Cívico Militar Professor Veríssimo de Melo dispõe de equipamentos, mobiliários, materiais didáticos e pedagógicos condizentes com as salas do tipo I. Os recursos que abrangem essa nomenclatura de sala são adequados e direcionados para atender alunos da Educação Básica que, necessitam de algum atendimento educacional especializado de natureza pedagógica para complementar a escolarização não suprida na sala comum. Os materiais são bem diversificados e conseguem ajudar no desenvolvimento de alunos que apresentam deficiência Intelectual, deficiência física neuromotora, transtornos globais do desenvolvimento e transtornos funcionais específicos, matriculados na Rede Pública de Ensino, após atender todos os critérios são atendidos na sala.

O ambiente denominado de SRM foi implantado nesta escola em fevereiro de 2014. Entretanto, somente depois de alguns meses começou o seu funcionamento efetivo com a chegada da professora que seria responsável pelo atendimento dos alunos. Anteriormente a essa chegada, os materiais didáticos eram utilizados por professores das salas comuns na tentativa de conseguir melhorar o processo de ensino aprendizagem dos alunos com deficiência.

Os Recursos Multifuncionais oferecidos pelo MEC para a Implantação e funcionamento do Programa da sala de AEE podem ser visto do quadro I a segui, retirado de (BRASIL, 20Iо, p. II):

Quadror:Recursos para a implantação das salas multifuncionais

\begin{tabular}{|l|l|}
\hline Equipamentos & Materiais Didático/Pedagógico \\
\hline 02 Microcomputadores & 01 Material Dourado \\
\hline 01 Laptop & 01 Esquema Corporal \\
\hline 01 Estabilizador & 01 Bandinha Rítmica \\
\hline 01 Scanner & 01 Memória de Numerais I \\
\hline 01 Impressora laser & 01 Tapete Alfabético Encaixado \\
\hline 01 Teclado com colméia & 01 Software Comunicação Alternativa \\
\hline 01 Acionador de pressão & 01 Sacolão Criativo Monta Tudo \\
\hline 01 Mouse com entrada para acionador & 01 Quebra Cabeças - seqüência lógica \\
\hline 01 Lupa eletrônica & 01 Dominó de Associação de Idéias \\
\hline Mobiliários & 01 Dominó de Frases \\
\hline 01 Mesa redonda & 01 Dominó de Animais em Libras \\
\hline 04 Cadeiras & 01 Dominó de Frutas em Libras \\
\hline 01 Mesa para impressora & 01 Dominó tátil \\
\hline 01 Armário & 01 Alfabeto Braille \\
\hline 01 Quadro branco & 01 Kit de lupas manuais \\
\hline 02 Mesas para computador & 01 Plano inclinado - suporte para leitura \\
\hline 02 Cadeiras & 01 Memória Tátil \\
\hline
\end{tabular}

A escola já mencionada recebeu o material, porém, existe o desgaste pelo uso diário e a desatualização dos softwares computacionais, que nem sempre estão disponíveis para atualizações. Muitas vezes cabe a professora da sala de recursos adequar, confeccionar e disponibilizar materiais e conteúdos tanto para a sala de AEE quanto para o auxilio do professor regente da sala comum. 
Esse ambiente conjuntamente com todos esses recursos didáticos é um facilitador muito significativo no processo de ensino aprendizagem dos estudantes com alguma deficiência. Promovendo o desenvolvimento das funções psicológicas do público atendido, sendo as sensações, percepção, atenção, memória, imaginação, pensamento e a linguagem, as evoluções mais perceptíveis no desenvolvimento dos educandos. Muitos alunos percebem esses materiais como uma forma de brincar e essa brincadeira é uma atividade intrínseca do ser humano. Logo, eles conseguem realizar com mais facilidade as atividades e vencer os obstáculos enfrentados nas salas comuns, desenvolvendo o conhecimento e se apropriando dos conceitos pertencentes ao material trabalhado de uma forma lúdica e prazerosa onde sua deficiência deixa de interferir no ensino e na aprendizagem dos mesmos.

Em relação à aprendizagem, Vygotsky (2007, p. 103) evidencia que:

[...] o aprendizado adequadamente organizado resulta em desenvolvimento mental e põe em movimento vários processos de desenvolvimento que, de outra forma, seriam impossíveis de acontecer. Assim, o aprendizado é um aspecto necessário e universal do processo de desenvolvimento das funções psicológicas culturalmente organizadas e especificamente humanas.

Dessa forma, a nosso ver, a escola precisa oferecer diferentes formas de ensino e aprendizagem aos estudantes para propiciar um melhor desenvolvimento de todos no processo educativo.

\section{Sala de Recursos multifuncionais onde acontecem os AEE da ECIM}

Adiante seguem fotos da sala de AEE, no ano de 2020, mostrando alguns dos equipamentos e materiais didáticos que a compõe desde sua implantação. Também constam nas imagens, materiais confeccionados pela professora da sala multifuncional, a qual recebe e orienta os professores das salas regulares quanto ao acompanhamento conjunto entre $\mathrm{AEE}$ e esses profissionais das salas comuns em relação ao aluno público-alvo desse atendimento.

Nas fotos i e 2, temos uma visão mais ampla desse ambiente mostrando os computadores, a impressora, a mesa redonda, o conjunto de carteiras e cadeiras, alguns materiais didáticos e um Datashow (não faz parte dos materiais recebidos para a implantação da sala de AEE, porém, é utilizado na sala como uma ferramenta facilitadora do aprendizado). Como pode ser observado a seguir:

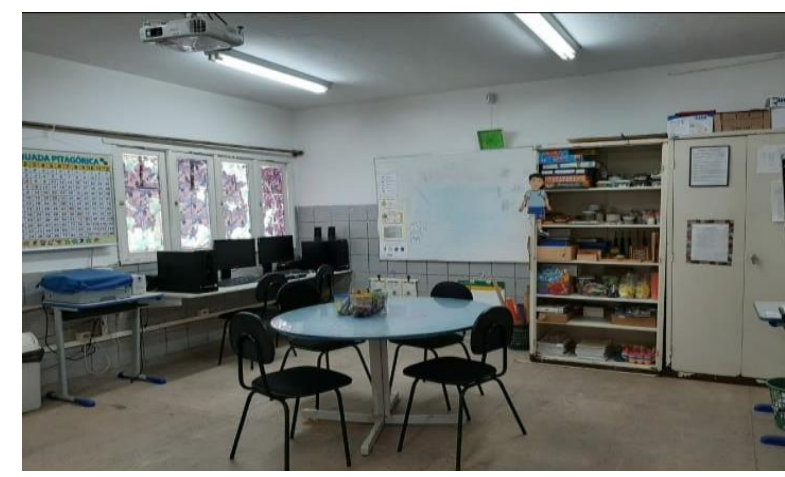

Foto I

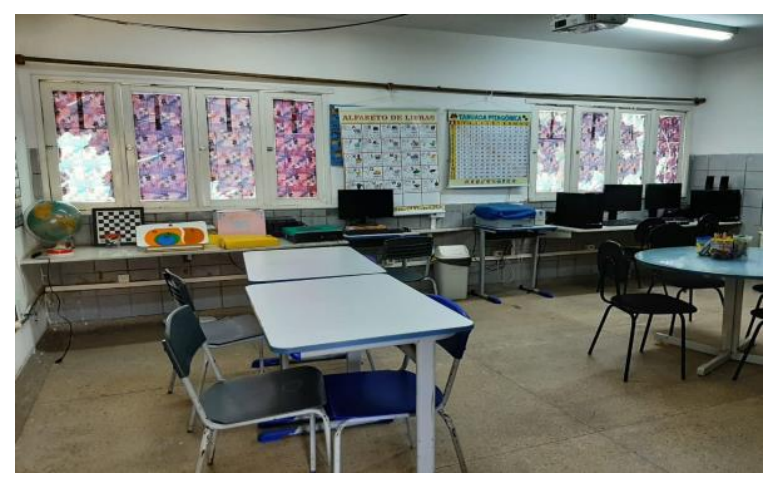

Foto 2

Fonte: Foto r e 2: professora regente da sala de recursos Elisimar Lopes da silva. 
Já na foto 3, mostramos computadores e teclados com colmeia. Esse tipo de material apresenta uma placa de plástico ou acrílico com perfurações correspondentes a cada tecla do teclado, que quando fixada a uma certa distância acima deste, tem por finalidade evitar que a pessoa que apresenta movimentos involuntários pressione teclas indesejadas. Esse material é muito utilizado para facilitar o processo de ensino-aprendizagem de alunos que tem o diagnóstico da paralisia cerebral.

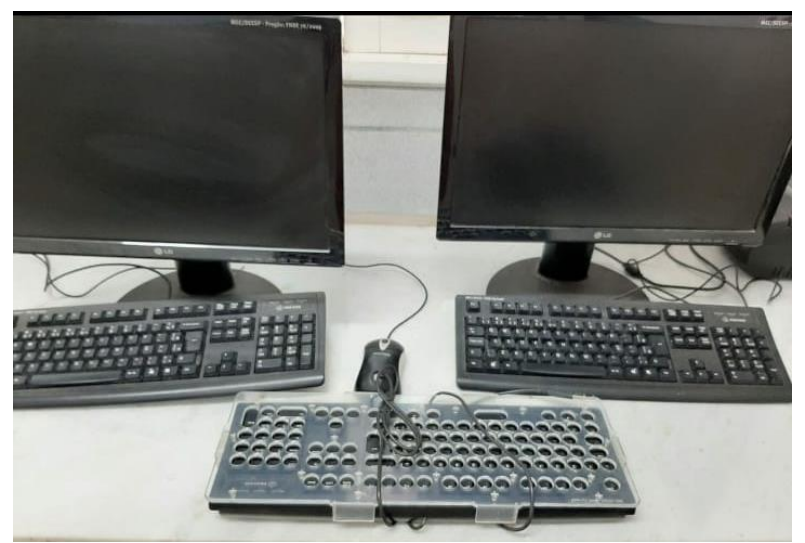

Fonte: Foto 3: professora regente da sala de recursos Elisimar Lopes da Silva.

A foto 4 expõe o Kit de lupas manuais. Esse material possibilita aos alunos com baixa visão um melhor acesso as atividades.

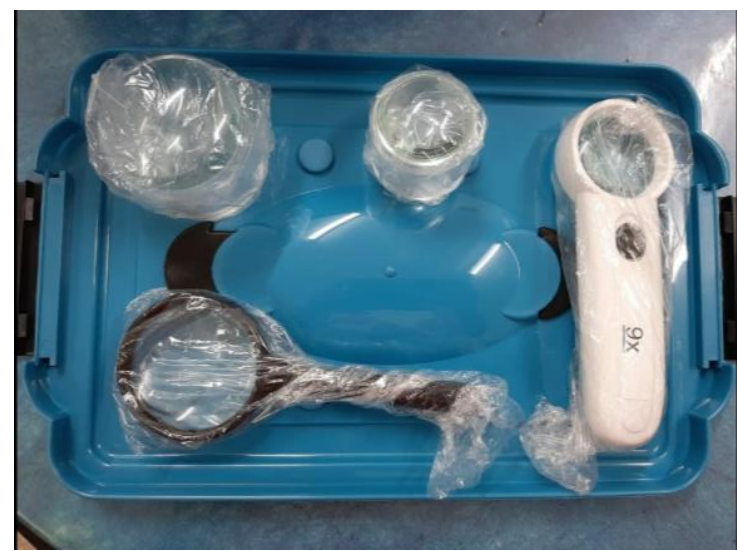

Fonte: Foto 4: professora regente da sala de recursos Elisimar Lopes da Silva.

Nas Fotos 5 e 6, temos os jogos didáticos pertencentes ao ambiente da sala de AEE. $\mathrm{O}$ material mencionado tem a finalidade de facilitar o ensino-aprendizagem desses educandos que necessitam de Atendimento Educacional Especializado diferenciado e auxiliam na formação do pensamento teórico metodológico. Além disso, proporciona um melhoramento em relação ao aspecto da socialização, da coordenação motora, e outras possibilidades proporcionadas pelo jogo. 


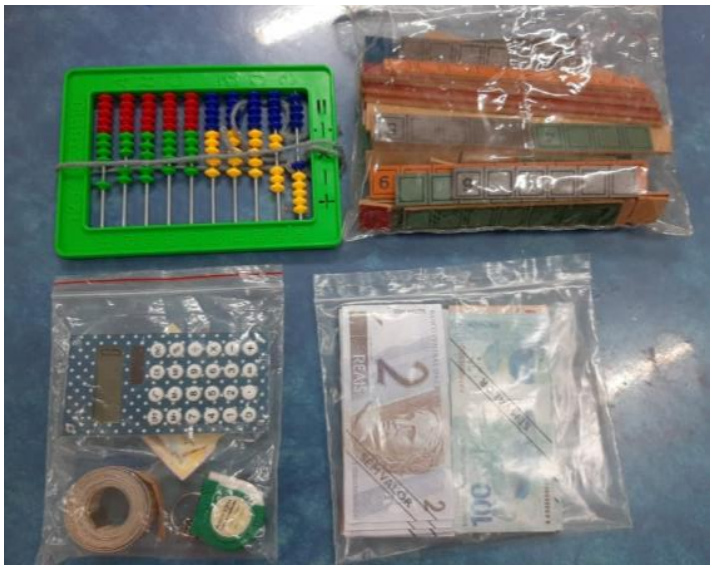

Foto 5

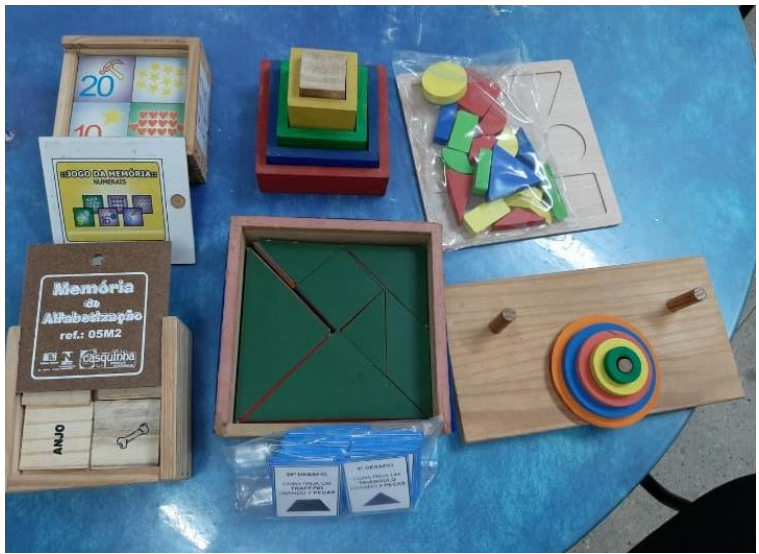

Foto 6

Fonte: Foto 5 e 6: professora regente da sala de recursos Elisimar Lopes da silva.

\section{CONSIDERAÇÕES}

Nesse artigo, tivemos a intenção de compreender um pouco como se deu a evolução da educação inclusiva no Brasil, enfatizando a proposta anunciada pelo MEC para o trabalho docente nas SRM para o AEE junto aos alunos com alguma deficiência. Para isso tivemos embasamento em alguns documentos representativos da educação especial na perspectiva inclusiva.

A SRM é uma conquista de grande importância para os alunos com deficiência que necessitam de um atendimento especializado, porém acreditamos que mais recursos deveriam ser destinados a esse programa e as escolas que foram selecionas para fazer parte dele. Em nosso entendimento, todas as escolas pertencentes ao programa mencionado deveriam ter uma equipe multifuncional para atender esses alunos, pelo menos periodicamente. Assim, eles teriam uma oportunidade de melhorar o seu desenvolvimento de forma mais global, sendo atendido por uma equipe especializada que poderia mais facilmente trabalhar suas respectivas necessidades com os direcionamentos mais adequados. O trabalho que é desenvolvido pela professora desta sala é excelente mesmo não tendo todos os recursos que de fato deveriam ser disponibilizados. Por isso, acreditamos que o serviço realizado por estes profissionais poderia ser ainda melhor se tivessem o aporte como rege a lei. Desse modo, teríamos uma educação inclusiva de qualidade onde toda a sociedade seria beneficiada com uma educação pública, de qualidade e igualitária para todos.

E acrescentamos ainda que, existe a necessidade de as escolas terem uma equipe multifuncional especializada que possam fazer uma triagem desses alunos que, mesmo sem um laudo médico, são perceptíveis que tem essa carência de um acompanhamento educacional especializado diferenciado. Visto que, muitas vezes, esses estudantes são prejudicados educacionalmente porque a família não consegue o laudo por falta de informações e/ou condições financeiras de obtê-lo.

\section{REFERÊNCIA}

BRASIL. [Constituição 1988]. Constituição da República Federativa do Brasil. Brasília: Senado Federal: Centro Gráfico, 1988. 
BRASIL. Manual de Orientação do Programa de Implantação de Sala de Recursos Multifuncional. SEESP/MEC, 2010.

Ministério da Educação/Secretaria de Educação Especial. Programa de implantação de salas de recursos multifuncionais. Edital № or de 26 de abril de 2007 .

BRASIL. Ministério Da Educação. Secretaria de Educação Especial. A educação especial na perspectiva da inclusão escolar. Universidade Federal do Ceará, 20ı. v. I.

BRASIL. Base Nacional Comum Curricular: Educação Infantil e Ensino Fundamental. Brasília: MEC/Secretaria de Educação Básica, 2018. Disponível em: http://basenacionalcomum.mec.gov.br/images/BNCC_EI_EF_IIO518_versaofinal_site.pdf. Acesso em: 22 jan. 2020.

DECLARAÇÃO DE SALAMANCA: Sobre princípios, políticas e práticas na área das necessidades educativas especiais. Salamanca-Espanha, 1994. Disponível em: http://www.pnl2027.gov.pt/np4Admin/\%7B $\$$ clientServletPath\%7D/?newsId= Iori\&fileN ame=Declaracao_Salamanca.pdf. Acesso em: 22 jan. 2020 .

DIRETRIZES E BASES DA EDUCAÇÃO NACIONAL - Lei Nº 9.394/96. Disponível em: http://www.planalto.gov.br/ccivil_03/leis/l9394.htm Acesso em: 26 nov. 2019.

III CONEDU CONGRESSO NACIONAL DE EDUCAÇÃO, A EVOLUÇÃO DA EDUCAÇÃO ESPECIAL NO BRASIL: PONTOS E PASSOS. Disponível em: http://www.editorarealize.com.br/revistas/conedu/trabalhos/TRABALHO_EVo56_MDI _SAi4_IDi304_IIO82016230920.pdf. Acesso em: 22 jan. 2020.

DUTRA. Claudia Pereira; GRIBOSKI. Claudia Maffini; Educação Inclusiva: um projeto coletivo de transformação do sistema educacional. In: BRASIL. Ministério da Educação. Ensaios Pedagógicos: III seminário nacional de formação de gestores e educadores. Brasília: Ministério da Educação, 2006.

MANTOAN, Maria Teresa Eglér. Igualdade e Diferença da Escola: Como Andar no Fio da Navalha. In: ARANTES. Valéria Amorim. Inclusão social. São Paulo: Summus, 2006. p. 15-30.

SILVA, T. T. da. (Org.). Identidade e Diferenças: A perspectiva dos Estudos Culturais. Petrópolis: Vozes, 2000.

VIGOTSKI, L. S. (Org.). A formação social da mente: O desenvolvimento dos processos psicológicos superiores. 7. ed. São Paulo: Martins Fonte, 2007. 